\title{
The influence of uncertainties of infill panels relative to the seismic response of $\mathrm{RC}$ existing buildings
}

\author{
A. Fiore, F. Porco, G. Uva \& M. Sangirardi \\ DICATECh, Politecnico di Bari, Italy
}

\begin{abstract}
Macro-modelling approaches are widely used for assessing the effects of infill panels. However, they contain some specific uncertainties concerning the definition of the equivalent strut (such as the width of the strut, the non-linear constitutive law under cyclic actions and assignment of mechanical properties in multiple strut models) that causes the variability of global structural response. As a result, there is the need to identify what are the parameters that influence the overall response of the building. After the identification of significant parameters, it is crucial to quantify the variation of the results regarding the safety verification of the building. In order to investigate this aspect, for two existing buildings with different heights, using a range of permissible values, the characteristic points (yield strength and maximum point) of the cyclic non-linear law were changed. The procedure has been carried out with the other preliminarily fixed parameters of the equivalent struts. With this approach, a variation of the safety in performance terms was assessed by carrying out a sensitivity analysis of the non-linear cyclic law. The results proposed lay the foundations for further consideration of issues relating to the modelling uncertainties and the development of simplified models for the assessment of existing structures designed to withstand only vertical loads.

Keywords: infilled frames, existing buildings, non linear static analysis, earthquakes, dynamic loading, seismic assessment.
\end{abstract}

\section{Introduction}

In the design of reinforced concrete buildings the contribution in terms of strength and stiffness of the non-structural elements, such as infilled panels, it is 
usually neglected. The current regulations (Italian technical rules and Eurocodes) favour this trend and push to consider the infill wall as a "disconnected element" from the frame. However, the seismic response of existing RC structures is strongly influenced by the infilled frames. The observation of damage, in areas affected by the recent earthquakes, has confirmed that their contribution to global resistance is crucial for the formation of the collapse mechanism of the frame [1]. In regular structures, the notable stiffness and/or any irregularity of the infills (in height or in plan) can produce "local" effects, which can often occur suddenly do to brittleness behaviour of reinforced concrete elements. Consequently, the seismic improvement interventions in areas affected by strong earthquakes place particular emphasis on masonry panels and their connection to the elements of the surrounding frame [22].

It is clear that the way of considering the infills is substantially different depending on the scope in which it falls: for example a new construction or the verification of an existing structure. As a result, the current discussion about the non-structural elements, neglecting the final objectives of the structural analysis, can be linked to the effects induced by the infill panels into the modelling. During the design phase of the numerical model, the introduction of the masonry panel as a simple structural element, and finding a model than can be adequately cope with the effects produced by the local and global behaviour of the boundary frame, becomes important.

1) The heterogeneous characteristics of the panel, resulting from the diversity of the constituent materials (brick and mortar), make the definition a stressstrain relationship difficult.

2) The anisotropic characteristics of the materials make the prevision of the nonlinear behaviour of the infilled frame, therefore, it is not possible to predict in advance what the collapse mechanism of the global system is difficult.

3) The connection between the frame and panel at the interface, the laying of the masonry panel in the execution phase and the maintenance during its useful life, are all factors that aren't easily estimable, but they certainly influence the behaviour of infilled frame.

4) The parameters that affect the global kinematic of the frame-panel system are numerous and often difficult to assess.

It is therefore clear that a mathematical model of phenomenon influenced by so many factors, leads to some uncertainty caused by the need to simplify the problem by only defining few characteristic parameters. Literature has provided different models over the years. They involve several parameters which are particularly influenced by the above factors.

In this context, the macromodels have a prominent role. They allow a considerable reduction of the parameters involved in favour of a easily used model which only depends on the geometrical and mechanical variables characterizing the equivalent strut (beam element) that simulates the infill (width $b_{\mathrm{W}}$, stiffness and non-linear cyclic law force-displacement). A disadvantage is a wide variability of the results $[2,3]$. If we add the contribution of the technical research, which over the years has provided many formulations for the 
calibration of these variables in order to capture aspects related to the failure mode of the panel (difficult to predict in the modelling phase) and local effects (at the ends of the columns), the degree of uncertainty in the results obtained greatly increases [4]. In the last few years, several research studies have been devoted to the appraisal of uncertainty in the analysis of infilled frame structures, many of which have proposed sensitivity analyses about the different variables involved in the response of the infilled frame $[5,6]$.

Having a complete picture of the problem, it also becomes important to quantify the level in which the uncertainties, deriving from the analysis with macromodels, affect the safety checks on the building. The main objective of this work is to quantify the variation of the structural capacity in displacement terms through a sensitivity analysis on the non-linear cyclic law of infilled frames. The analytical study is to compare the pushover curves, obtained by the analysis of finite element models of two structural benchmarks of different heights, in which the infills were simulated by equivalent diagonal struts. For both case studies, the characteristic points (yield strength and maximum resistance value) of the constitutive law of each infilled frame were varied within a range of fixed values, keeping all other parameters constant. The results collected in the end section of the work, provide further considerations about the problems linked to uncertainties in the modelling of infills. They represent the starting point for developing simplified models for the evaluation of existing structures designed only for withstanding gravitational actions.

\section{Non-linear modelling of infill panels}

With regard to frame-infill systems, many models have been proposed in the literature. The equivalent diagonal strut method $[7,8]$ is based on the observation that, within a masonry panel, the compressive stress substantially follows the diagonal path, and thence adopts one or more equivalent diagonal struts in order to simulate the infill masonry panel. The fundamental parameters of the methods are represented by the geometric features of the strut (diagonal length $d_{W}$, thickness $t_{W}$ and width $b_{W}$ ), the stiffness $\lambda$, the hysteretic constitutive law $F_{W}-S$ ( $F_{W^{-}} d$ in the figure) which governs the non linear cyclic behaviour of the panel (Figure 1).

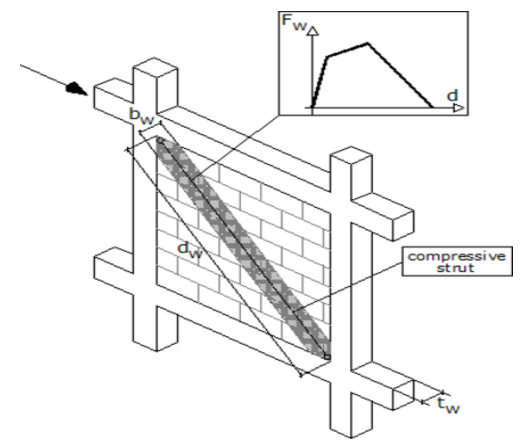

Figure 1: The equivalent diagonal strut model. 
Extensive literature can be found about the choice of the geometric characteristics of the panel in order to achieve the equivalence in terms of strength and stiffness. The thickness of the strut is usually assumed to be the same of the panel, whereas different proposals have been made with regard to the width $b_{W}$. Basically, there are two main approaches. A first one simply defines $b_{W}$ as a function of the diagonal length of the panel, giving more emphasis to the geometric aspects than to the mechanical ones [9]. The second approach, instead, defines the parameters of the equivalent strut on the basis of both the geometry and the mechanical properties of the infilled frame providing more refined numerical formulations [10]. The first author to work in this direction was [11], who introduced on the basis FEM numerical analyses a parameter $\lambda$ expressing the relative stiffness of the frame and of the panel:

$$
\lambda=\sqrt[4]{\frac{E_{W} t_{W} \sin 2 \theta}{4 E_{C} I_{P} H_{W}}}
$$

where: $E_{W}$ and $E_{C}$ respectively are, the elastic modulus of the infill panel and of the RC frame; $t_{W}$ is the thickness of the panel; $I_{P}$ is the moment of inertia of the column; $H_{W}$ is the height of the panel; $\theta$ is the slope angle of the panel's diagonal. Klingner and Bertero [12] resumed the above-mentioned study, performing laboratory tests on scale models (1:3) that reproduced RC frames and infill panels made by hollow concrete/brick masonry. They obtained the following expression for the width $b_{W}$ of the equivalent strut, as a function of the stiffness parameters $\lambda$

$$
b_{W}=0,175 d_{W}\left(\lambda H_{W}\right)^{-0,4}
$$

With regard to the hysteretic law $F_{W} S$ which describes the cyclical behaviour of the strut under axial loads, several models can be found in the literature, which are derived from the phenomenological observation of experimental tests in which scale models are dynamically brought to collapse. Among the different proposals, examples can be found in which the law is expressed in terms of axial strain/stress [13]. There are also formulations in which, regardless of the geometrical and mechanical characteristics of the infill, a predominant failure mode (which can consist in the crushing at the centre or at the corners of the panel) is a-priori defined [14].

In Figure 2, the parameters defining the different branches of the curve are specified:

- Initial shear stiffness $K_{l}$ of the uncracked panel:

$$
K_{1}=\frac{G_{W} t_{W} L_{W}}{H_{W}}
$$

$G_{W}$ is the tangential elastic modulus of the masonry infill; $L_{W}, H_{W}$ and $t_{W}$ respectively are the length, the height and the thickness of the panel.

- Yielding force $F_{y}$ corresponding to the first cracking of the panel:

$$
F_{y}=f_{t p} t_{W} L_{W}
$$

$f_{t p}$ is the tensile strength of the panel, evaluated by the diagonal compression test

- Axial stiffness $K_{2}$ of the equivalent strut:

$$
K_{2}=\frac{E_{m} b_{W} t_{W}}{d}
$$


- Maximum force $F_{m}$, assumed as $1.3 F_{y}$.

- Displacement $S_{m}$ corresponding to the maximum force:

$$
S_{m}=S_{y}+\frac{F_{m}-F_{y}}{K_{2}}
$$

Stiffness of the softening branch, which can be assumed within the range $0.005 K_{l} \leq K_{3} \leq 0.1 K_{l}$. Residual force $F_{r}$ in order to guarantee the numerical stability, it can be assumed $0 \leq F_{r} \leq 0.1 F_{y}$. In the proposed case studies, the residual force is assumed to be 0 . Some authors have assigned for ultimate displacement $S_{r}\left(\right.$ or $\left.S_{u}\right)$ corresponding to the residual force, a value deriving to ratio $\mathrm{S}_{\mathrm{r}} / \mathrm{S}_{\mathrm{m}}=5$.

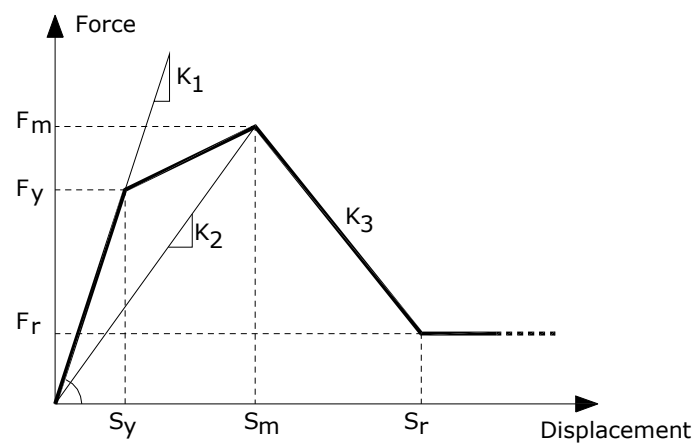

Figure 2: The force-displacement relationship proposed by Panagiotakos and Fardis [14] for the equivalent strut model.

However, the experimental evidence has pointed out that crushing represents only one of the possible failure modes of the infill panel. Thence, it should be first necessary to evaluate the ultimate load associated to each of the possible failures, and then to calculate the strength of the panel as the minimum of these loads. Some proposals in this direction, based on semi-empirical approaches, identify a set of different failure modes (3, 4 or 5) of the infill panel subjected to horizontal in-plane loads [15-17]. These empirical formulations involve a large number of parameters, and this makes their application quite cumbersome.

The equivalent model with a single strut is a simplified representation of the "non structural" panel within the frame, but is not able to describe the "local" interaction between the infill panel and the surrounding structural elements in the proximity of the nodes. This is a critical point in the buildings dated back to the $70 \mathrm{~s}$, where the distribution of stirrups within the structural elements is typically poor and ineffective. This issue is specifically dealt by many research studies that can be found in the literature, most of which are based on the use of multiple parallel strut $[13,18])$. The actual difference is only given by the dimension of the transversal section and by the stiffness, which is properly shared among the struts. 


\section{Analysis on the nonlinear cyclic law of the equivalent strut}

As mentioned in the introduction, this study aims to quantify the variability of the structural capacity as a result of a specific analysis on the cyclic law of the equivalent strut. The analysis consists in varying the characteristic points of the law (point $\mathrm{S}$ and $\mathrm{M}$ in Figure 3) in a range such as to alter the trend of forcedisplacement law. The blue dashed lines are produced by a variation of the mechanical properties of materials of a maximum quantity of $50 \%$.

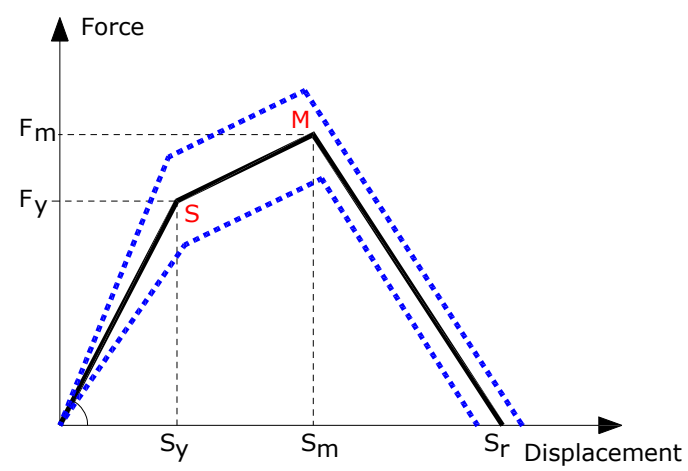

Figure 3: Variation of the nonlinear cyclic law.

The constitutive relationship adopted for the aim of the research is the trilinear law proposed by Panagiotakos and Fardis [14] (shown in Figure 2). The maximum amplitude of the variation range adopted is calibrated on the basis of the mechanical properties of the panel, and more specifically of $E_{W}, G_{W}$ and $f_{t p}$, respectively, Elastic Modulus, Tangential Elastic Modulus and Shear Resistance. The mechanical parameters are preliminarily fixed on the basis of the constitution of the infill panel and they allow to obtain the starting position of the characteristic points of the law $(S$ and $M)$. Considering a maximum variability of the parameters equal to half of their initial value, five constitutive laws were defined for single equivalent strut, each of which corresponds to the mechanical parameters of the infill panel modified, respectively, of $-50 \%,-25 \%$, $0 \%,+25 \%$ to $+50 \%$.

\section{Cases of study}

To assess the effects on the structural capacity induced by the variation of the characteristic points of the non linear cyclic law of each strut, were made two benchmarks of a reinforced concrete building. This structure is referable for dimensions and mechanical properties at a predominant typology found from a study of the seismic vulnerability on territorial scale in the Province of Foggia (Italy) [22]. Benchmarks are two structures substantially quite different: a short building (SB) and a tall building (TB). This choice was adopted in order to capture any differences of the structural capacity due to the height of the building. 


\subsection{A short description of benchmarks}

The building has a set of reinforced concrete frames with masonry infill, arranged. The structural stiffness is uniformly distributed along two main directions. The building plan is rectangular, with a symmetry prevalent axis in the $\mathrm{X}$ direction. The structural plan can be considered as sufficiently regular and ascribable to a rectangular having sizes $17.05 \mathrm{~m} \times 24.80 \mathrm{~m}$.

The SB model has three floors, the first on the ground floor for offices and the other two for residential use, reaching an overall height of $9.60 \mathrm{~m}$. The TB building has an intended use equivalent to the SB structure but in opposition extends for a height equal to twice (6 floors in total), reaching a total height of $18.75 \mathrm{~m}$. The floors have a mixed structure made up by cast-in place concrete, precast lattice joists and hollow tile bricks, for a total height of $25 \mathrm{~cm}$. The columns are all of sizes $30 \mathrm{~cm} \times 50 \mathrm{~cm}$. The beams at the first floor are $30 \mathrm{~cm}$ wide and $50 \mathrm{~cm}$ height, while from the second floor are $30 \mathrm{~cm}$ wide and $50 \mathrm{~cm}$ height but there are also transversal sections $70 \mathrm{~cm}$ wide and $25 \mathrm{~cm}$ height. The concrete has an average compressive strength equal to $25 \mathrm{MPa}$, and the yield strength of steel rebars is $315 \mathrm{MPa}$. In the structural elements ribbed rebar were used as reinforcement. At the end sections of the beams, the longitudinal reinforcement consist in $4 \mathrm{f} 14$ on the top and $3 \mathrm{f} 14$ on the bottom, while for beams with height equal to $25 \mathrm{~cm}$ the reinforcement consists, respectively, in $5 \mathrm{f} 14$ and $4 \mathrm{f} 14$. Columns have a longitudinal reinforcement of $8 \mathrm{f} 16$, uniformly distributed on the sides, plus a transversal reinforcement provided by 18 stirrups, uniformly spaced every $20 \mathrm{~cm}$.

The mechanical properties of infill panels were assumed following the values provided in the C8.A.2 of the Italian Ministerial Circular 617/2009 for masonry in expanded clay blocks with percentage of holes between $45 \%$ and $65 \%$. Specifically, the starting values of $\mathrm{E}_{\mathrm{W}}, \mathrm{G}_{\mathrm{W}}$ and $\mathrm{f}_{\mathrm{t}}$ that will be modified according the intervals of $\pm 50 \%$ and $\pm 25 \%$ are, respectively, $1400 \mathrm{MPa}, 350 \mathrm{MPa}$ and $0.11 \mathrm{MPa}$.

\subsection{Modeling of buildings}

The numerical modelling was carried out by implementing proper spatial models of the building's structure within the FE solver "SAP2000" [19]. In particular, 2 three-dimensional models of the building have been initially considered: one for the analysis of the bare frame; one for the analysis of the structure in the actual configuration (with infill panels). In order to evaluate the behaviour of the structure with the infill panels, five different numerical models were employed all deriving by the variation of the mechanical properties of infills in according with the manner described previously. Each model was replicated 4 times by placing the equivalent strut equivalent, from time to time, along the direction and orientation of the thrust, so as to be reacting only under compression. Therefore, the numerical models used are globally 20 for each benchmark (Figure 4 a view of the two three-dimensional models). 

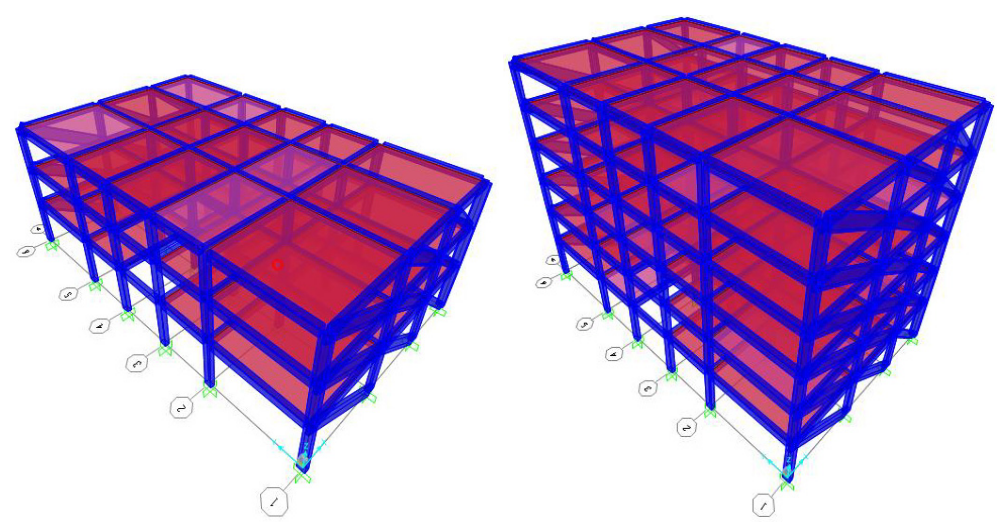

Figure 4: SB model (left) and TB model (right) for pushover analysis in $\mathrm{X}$ direction.

With regard to the constitutive laws for the materials, the classical parabolarectangle diagram has been adopted for the concrete under compression, and an elastic - hardening diagram has been adopted for the steel. The non linear behaviour of columns and beams was described according to a lumped plasticity approach, introducing plastic hinges, in which all non linearity is concentrated, at the end-sections of the elastic beams. The non linear behaviour of columns and beams is described according to a lumped plasticity approach, in which the frame elements are elastic. All nonlinearities are concentrated at the end-sections of the beams, in a plastic hinge that is defined by a proper non linear $M-\phi$ (or $M-\theta$ ) relationship. In this paper, the nonlinear constitutive law assumed for the plastic hinges is the one proposed by FEMA-356 [20] provisions (see Table 6.7 "Modelling Parameters and Numerical Acceptance Criteria for Nonlinear Procedures - Reinforced Concrete Columns").

The hysteretic constitutive law $F_{W}-S$ of the strut model have been assumed according to the model of Panagiotakos and Fardis [14]. The thickness of each strut coincides with that of the correspondent masonry panel, and the length is equal to the diagonal of panel whereas the width of the strut $b_{W}$ is obtained by eqn (2). In Figure 5 is shown the variation of the non linear law of the equivalent strut $X 1$ that simulates the panel of greater width, located on the ground floor in $\mathrm{X}$ direction. The five laws are obtained by varying the starting values of mechanical properties of the masonry infill of $\pm 50 \%$ and $\pm 25 \%$.

\section{Results}

The non linear analyses were performed to determine the pushover curves in the $\pm \mathrm{X}$ and $\pm \mathrm{Y}$ directions. This paper collects only results of the analysis in $+\mathrm{Y}$ direction (that is particularly significant because there are more infill panels than the $\mathrm{X}$ direction). The Structural Capacity has been calculated by non linear pushover analysis at the Limit States of Damage Limitation (DL), Life Safety (LS) and Near Collapse (NC) for all considered models. The above mentioned 


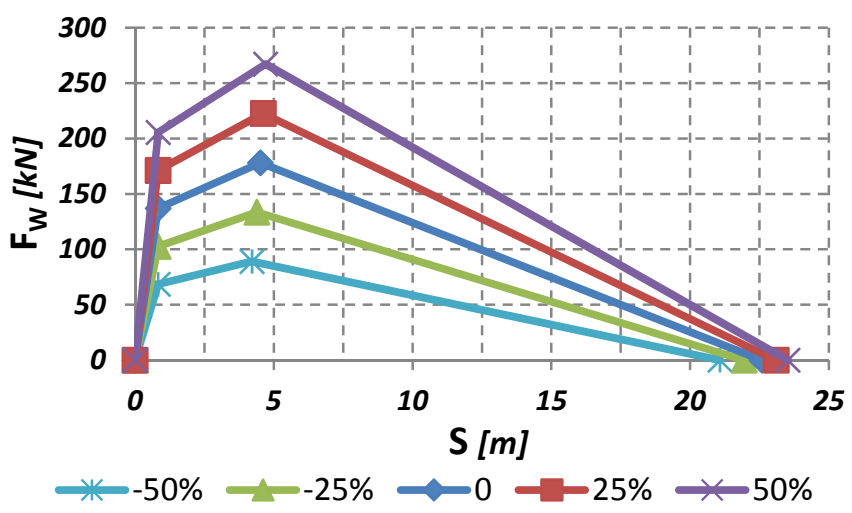

Figure 5: FX1 equivalent strut - variation of the force-displacement relationship.

limit states have been assumed to correspond to the attainment in the first of the primary structural elements (columns) of the characteristic values of the plastic hinges (see paragraph 4.2 above).

The graphs below show the structural capacity in terms of displacement at the limit state DL and CP, both for the TB model (Figure 6), both for the SB model (Figure 7). Each graph shows the range of variation of the structural capacity at limit state considered. In correspondence with a slight structural damage (DL), by varying the mechanical properties of the infill of $50 \%$ (of half or twice) the structural capabilities are contained in a maximum range of $\pm 8 \%$. While at the collapse of the first columns, the structural capacity varies by \pm $20 \%$. In addition, for each limit state, the differences in moving from a short to a tall structural type are negligible.

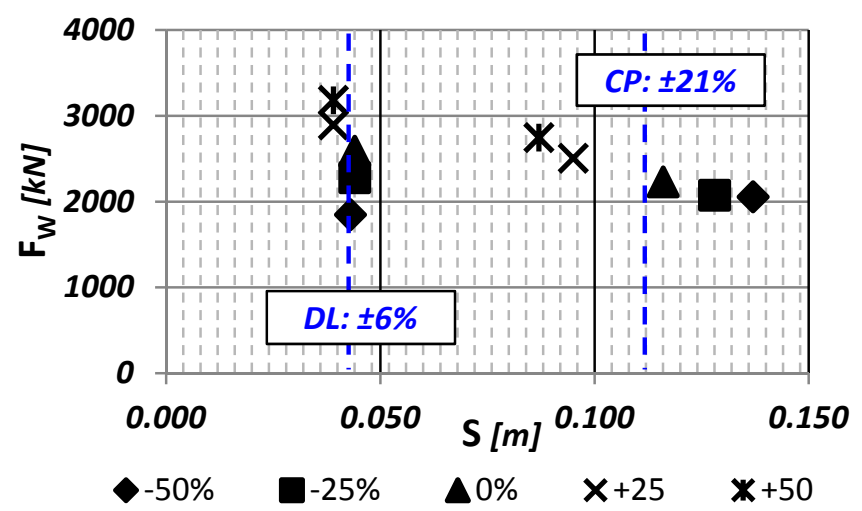

Figure 6: Structural capacity of TB model for DL and CP limit state. 


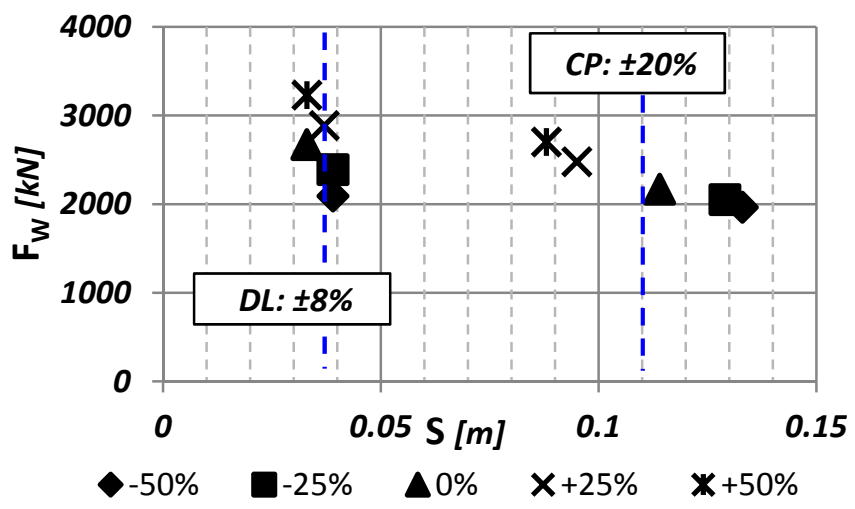

Figure 7: Structural capacity of SB model for DL and CP limit state.

\section{Conclusion}

In the context of the macromodelling of infill panels, this paper investigates the variability of Structural Capacity due to the variation of the nonlinear cyclic law of equivalent strut. The analytical study is carried out with the results of pushover analysis obtained on two specially built benchmarks. These have similar features to existing building designed for withstanding mainly vertical loads. The results show that, at structural damage, although the mechanical properties of the infills vary until to $50 \%$, the Capacities oscillate in a maximum range of $\pm 8 \%$. While at the collapse the maximum oscillation is equal to $21 \%$.

Therefore for low intensity earthquakes, the structural capacity of regular buildings, tends to be detached from mechanical characteristics of the infills, while depends much more at the collapse limit state. The study represents a starting point for further investigation on the problem of uncertainties in the modeling of infilled frames. At the same time it provides important information on the global behaviour of the models with infill panels for high intensity earthquakes.

\section{References}

[1] Braga, F., Manfredi, V., Masi, A., Salvatori, A., Vona, A. Performing of non-structural elements in RC buildings during the L'Aquila 2009 earthquake. Bulletin of Earthquake Engineering, 9(1), 307-324, 2009.

[2] Fiore, A., Porco, F., Raffaele, D., Uva, G. About the influence of the infill panels over the collapse mechanisms activated under pushover analyses: two case studies. Soil Dynamics and Earthquake Engineering, 39, 11-22, 2012.

[3] Uva, G., Porco, F., Fiore, A. Appraisal of masonry infill walls effect in the seismic response of RC framed buildings: a case study. Engineering Structures, 34(1), 514-26, 2012. 
[4] Uva, G., Porco, F., Raffaele, D., Fiore, A. On the role of equivalent strut models in the seismic assessment of infilled RC buildings. Engineering Structures, 42, 83-94, 2012.

[5] Celarec, D., Dolsek, M. The impact of modelling uncertainties on the seismic performance assessment of reinforced concrete frame buildings. Engineering Structures 52: 340-354, 2013.

[6] Celarec, D., Ricci, P., Dolsek, M. The sensitivity of seismic response parameters of the uncertain modeling variables of masonry-infilled reinforced concrete frames. Engineering Structures 35: 165-177, 2012.

[7] Mainstone, R.J. Supplementary note on the stiffness and strength of infilled frames. Current paper CP13/74. Build. Res. Establishment. London, 1974.

[8] Stafford Smith, B. Lateral Stiffness of infilled frames. Journal of Structural Division, ASCE, 6, 183-99, 1963.

[9] Holmes M. Steel frames with brickwork and concrete infilling. Proc. of the Institution of Civil Engineers, part 2, vol. 19, pp. 473-478, London, 1961.

[10] Dawe, J.L., Seah, C.K.. Analysis of concrete masonry infilled steel frames subjected to in-plane loads. Proc. of the $5^{\text {th }}$ Canadian Masonry Symposium, pp. 329-340, Vancouver, 1989.

[11] Stafford Smith, B. Behaviour of square infilled frames. Journal of the Structural Division, 92(1): 381-403, 1966.

[12] Klingner, R.E. \& Bertero, V.V. Infilled frames in earthquake-resistant construction. Report EERC 76-32, Earthquake Engineering Research Center, 1976.

[13] Crisafulli, F.J. Seismic behaviour of reinforced concrete structures with masonry infills. Ph.D. Thesis. Department of Civil Engineering, University of Canterbury, 1997.

[14] Panagiotakos, T.B. \& Fardis, M.N. Seismic response of infilled RC frames structures. Proc. of the $11^{\text {th }}$ World Conference on Earthquake Engineering; Paper No. 225, Acapulco, 1996.

[15] Saneinejad, A. \& Hobbs, B. (1995). Inelastic design of infilled frames, Journal of Structural Engineering, 121(4), 634-650.

[16] Liauw, T.C. \& Kwan, K.H. (1985). Unified plastic analysis for infilled frames. Journal of Structural Engineering, 111(7), 1427-1449.

[17] Bertoldi, S.H., Decanini, L.D. \& Gavarini, C. Telai tamponati soggetti ad azioni sismiche, un modello semplificato: confronto sperimentale e numerico (in Italian). Proc. of the $6^{\text {th }}$ ANIDIS Congress, vol. 2, pp. 815824, Perugia, Italy, 1993.

[18] El Dakhakhni, Elgaaly WW, Hamid AA. Three-strut model for concrete masonry-infilled steel frames. Journal of Structural Engineering 129(2): 177-85, 2003.

[19] Computer \& Structures. Sap2000, Advanced 14.2.2 Structural Analysis Program - Manual. Computer and Structures, Inc, Berkeley, California, USA, 2010. 
[20] FEMA 356. Prestandard and commentary for the seismic rehabilitation of buildings, 2000.

[21] Fiore, A., Porco, F., Uva, G., Mezzina, M. On the dispersion of data collected by in situ diagnostic of the existing concrete. Construction and Building Materials 47: 208-2017, 2013.

[22] Porco, F., Fiore, A., Uva, G., Raffaele, D. The influence of infilled panels in retrofitting interventions of existing reinforced concrete buildings: a case study. Structure \& Infrastructure Engineering 2013 -DOI: 10.1080/ 15732479.2013 .862726 . 